\title{
O CURRÍCULO DAS LICENCIATURAS EM MÚSICA: COMPRE- ENDENDO O HABITUS CONSERVATORIAL COMO IDEOLOGIA INCORPORADA
}

\author{
Marcus Vinícius Medeiros Pereira
}

\section{Resumo}

O texto apresenta análises parciais de projetos políticos pedagógicos de cursos de licenciatura em música brasileiros ancoradas na teoria crítica do currículo e na sociologia da cultura, especialmente nas proposições de Michael Apple e Pierre Bourdieu. As análises evidenciam uma ideologia musical incorporada na forma de um habitus, aqui chamado de habitus conservatorial que tem a música erudita como conhecimento oficial e como capital legitimado em disputa no campo em questão, determinando o sistema de cotação do que conta como conhecimento musical valorizado.

\section{Palavras-Chave:}

Licenciatura em Música; Currículo; Habitus Conservatorial.

O campo da teoria crítica, em educação, aborda as relações entre escolaridade, educação, cultura, sociedade, economia e governo. Como afirmam Popkewitz e Fendler (1999, p. xiii, tradução nossa), o projeto crítico em educação parte do pressuposto de que as práticas pedagógicas estão relacionadas às práticas sociais, e é tarefa do intelectual crítico identificar e resolver as injustiças nestas práticas.

Ao tomar como objeto de estudo os projetos pedagógicos dos cursos de Licenciatura em Música no Brasil, é preciso localizá-lo no centro destas tramas político-econômico-sociais, como construção ideológica e, por isso mesmo, não neutra.

Moreira e Silva (1995, p. 27) nos mostram que a ideia de cultura é inseparável da de grupos e classes sociais e, em uma sociedade dividida, "a cultura é o terreno por excelência onde se dá a

\section{Abstract}

This text presents partial analysis of some curricular documents of Brazilian music teacher education programs. This analysis is based in the curriculum critical theories and in the sociology of culture, especially in the propositions of Michael Apple and Pierre Bourdieu. The results show a musical ideology incorporated as habitus, which is called here conservatorial habitus that has the classical music as the official knowledge and as a legitimized capital in dispute in the field, classical music that also determines the quotation system of what counts as a valued musical knowledge.

\section{Keywords:}

Music Teacher Education Programs; Curriculum; Conservatorial Habitus.

luta pela manutenção ou superação das divisões sociais". O currículo educacional, por sua vez, é considerado por estes autores como o terreno privilegiado de manifestação deste conflito.

É necessário entender o currículo conforme Goodson (1999, p. 21) o define: "um testemunho visível, público e sujeito a mudanças, uma lógica que se escolhe para, mediante sua retórica, legitimar uma escolarização". O currículo procura justificar determinadas intenções básicas de escolarização à medida em que estas vão sendo operacionalizadas em estruturas e instituições. Logo:

[...] o currículo escrito nos proporciona um testemunho, uma fonte documental, um mapa do terreno sujeito a modificações; constitui também um dos melhores roteiros oficiais para a estrutura institucionalizada da escolarização. (GOODSON, 1999, p. 21).

Assim, o currículo é uma lógica escolhida por de- 
terminado grupo de acordo com o interesse deste grupo. o currículo não é, pois, “um elemento inocente e neutro de transmissão desinteressada do conhecimento social" (MOREIRA e SILVA, 1995, p. 7). Nele, relações de poder estão implicadas, e, a partir dele, visões particulares e interessadas estão sendo transmitidas. Moreira e Silva (1995) nos mostram que o currículo não é um elemento transcendente e atemporal: ele tem uma história, vinculada a formas específicas e contingentes de organização da sociedade e da educação.

Pensando nas licenciaturas em música, ao analisar suas propostas curriculares é preciso contextualizá-las historicamente, procurando desnaturalizar algumas questões centrais que envolvem a formação musical.

Ao participar de um momento de reformulação do projeto pedagógico do curso de Licenciatura em que trabalhava, percebi que determinado grupo de disciplinas não era passível de discussão: essas disciplinas eram fundamentais e naturalmente comporiam o currículo de qualquer instituição que trabalhasse com música.

Não casualmente, esse grupo de disciplinas se enquadraria no tópico "Conhecimentos Específicos" definido pelas diretrizes curriculares nacionais para os cursos de graduação em Música (2004) como "estudos que particularizam e dão consistência à área de Música, abrangendo os relacionados com o Conhecimento Instrumental, Composicional, Estético e de Regência" (BRASIL, 2004, p. 2).

O curioso é que as diretrizes não determinam as disciplinas, definindo um currículo comum. Ao contrário, o documento valoriza a necessidade de os projetos pedagógicos dos cursos superiores em música levarem em consideração o contexto em que estão inseridos.

Entretanto, estes conhecimentos específicos são estruturados de maneira semelhante nos cursos de licenciatura em música brasileiros - e também sul-americanos (cf. MATEIRO, 2010): Teoria e Percepção Musical, Contraponto, História da Música, Harmonia, Análise, Piano, Instrumento Complementar.

É como se houvesse uma prescrição sobre como organizar os conhecimentos específicos da área de Música. Como se houvesse um modelo a ser seguido, ou melhor, um modelo a ser sempre atualizado.

E este modelo, embora naturalizado, não deve ser aceito como neutro. Precisa ser entendido como resultado de uma seleção arbitrária e interessada feita na/da/para a cultura. Ao ser atualizado nos currículos, esta maneira de pensar a formação musical torna-se uma definição oficial daquilo que conta como conhecimento válido e importante.

Retomando a questão da contextualização histórica dos currículos das licenciaturas em Música, é consenso na área a forte ligação e influência do Conservatório na organização daquilo que se define hoje como conhecimento musical.

No Brasil, o Conservatório Imperial de Música foi criado no século XIX, constituindo-se como um marco na história das práticas pedagógico-musicais do país. Essa importância não reside no fato do conservatório ter instituído práticas que perdurariam até hoje, mas, antes, por institucionalizar e legitimar práticas de ensino de música que vinham sendo praticadas no Brasil desde os primeiros anos de sua colonização.

Decorre desta afirmação que o Conservatório não "cria" práticas de ensino, apenas as reúne, organiza, sistematiza e, portanto, oficializa. A criação do Conservatório, no Brasil, trouxe benefícios não só para a classe profissional do país, mas foi importante para as intenções ligadas ao ideal de "Estado Moderno", imprimindo ao povo brasileiro um verniz de civilidade através da formação musical diletante das elites.

Institucionalizava-se a formação de músicos voltada para a prática instrumental e legitimava-se, ao mesmo tempo, a música erudita europeia como o conhecimento oficial que conferia distinção social para seus praticantes. Nada mais natural, uma vez que a Europa era o modelo de civilização e cultura da época.

Silva (2007, p. 31) corrobora esta afirmação, mostrando que a criação do Conservatório estava ligada a uma questão de defesa da ordem pública para conseguir o ideal da civilização, do progresso e da ordem social de forma pacífica:

A criação do Conservatório de Música como uma instituição oficial pode ser considerada dessa forma: Como um dos elementos que buscavam criar 
alternativas para a manutenção de uma ordem social que se tornava mais complexa e múltipla, agindo como um elemento unificador da cultura civilizadora, mas também uma alternativa - moderna e distinta - para a ampliação e restituição da intensa atividade musical da cidade do Rio de Janeiro que passava por um momento de atrofia dos principais organismos musicais da corte.

Desde o seu início, portanto, os ideais que permeavam a instituição conservatorial estavam ligados à distinção civilizadora e à formação de músicos. Esta ideologia será perpetuada em cada ato do jogo histórico do ensino de música no nosso país.

Vieira (2000) explicou essa perpetuação a partir do conceito de "modelo conservatorial". Ao estudar a formação de professores de música em Belém - PA, a autora liga este modelo ao domínio do código escrito como essencial à execução de um repertório determinado de música erudita:

A história da música permite, ainda, dar conta de que o código musical ensinado pelo modelo conservatorial corresponde ao conhecimento produzido à época em que este modelo foi criado. Ao conservar este conhecimento, o modelo conservatorial preserva um dos fatores que o fundamentam, qual seja, uma cultura musical que compreende elementos de uma música de um determinado momento histórico. Dessa forma, o modelo conservatorial tende a preservar as bases musicais com as quais se identifica, que correspondem à música erudita européia dos séculos XVIII e XIX. (VIEIRA, 2000, p. 4)

Jardim, V. (2008), de forma análoga, observa a consolidação de uma forma conservatorial presente na formação do "músico professor" - cuja formação era especializada, com caráter essencialmente técnico, estético, artístico e profissional (com forte apelo à performance).

Para a autora, na forma conservatorial o conhecimento teórico era considerado como o procedimento essencial para que o aluno já tivesse os rudimentos de leitura e escrita quando começasse a tocar ou cantar. Assim, adotava-se uma sequência de regras que deveriam ser decoradas pelo aluno, como condição inicial do aprendizado musical.

Jardim (2008) aponta ainda que tanto a forma conservatorial quanto as práticas de ensino a ela intrínsecas estariam tão arraigadas e vistas de forma naturalizada na formação do músico que, de um modo geral, as pesquisas que se ocupam deste tema dispensam a sua exposição, comentários, ou alusões a respeito. Para ela, colaboraram para a consolidação da forma conservatorial, para além das práticas de ensino, a própria estrutura dos cursos, os programas de ensino e o perfil dos alunos.

Entretanto, discordamos da ideia de que um modelo era reproduzido, como se não houvesse nenhuma reflexão a respeito. Vários estudos, como por exemplo o de Kleber (2000) e o de Denardi (2006), sinalizavam a necessidade de reformas nos documentos curriculares dos cursos de licenciatura estudados, mas, em geral, as alterações percebidas após estas reformas eram sempre periféricas, recaindo apenas sobre os nomes de disciplinas, alterações de cargas horárias e ementas. Assim, a essência da concepção curricular permanecia sempre a mesma.

Nesta perspectiva é que propusemos uma revisão disso que se chamava de reprodução de um "modelo" ou "forma" conservatorial. Pareceu-nos interessante oxigenar esta visão, propondo um conceito que explicasse a atualização das práticas tradicionais - e não a sua mera reprodução. Como se houvesse disposições internalizadas que, mesmo na proposição de mudanças e reformas, orientassem inconscientemente as práticas de maneira ainda bastante ligada à tradição - o que explicaria o caráter periférico e cosmético de tais "mudanças".

Uma ideologia musical seria, portanto, incorporada e constituída como matriz de ações e de percepções. E o currículo, entendido como resultado de práticas e crenças institucionalizadas e incorporadas, torna-se um produto onde estas podem ser mapeadas, permitindo a reconstrução da ideologia que orientou sua construção.

Giroux e Mc Laren (1995, p. 142) mostram que as escolas são as instituições históricas e culturais que sempre incorporam interesses ideológicos e políticos:

[...] as escolas são terrenos ideológicos e políticos a partir dos quais a cultura dominante "fabrica" suas "certezas" hegemônicas, mas são também lugares onde grupos dominantes e subordinados se definem e se reprimem mutuamente em uma batalha e um intercâmbio incessantes, em resposta às condições sócio-históricas "propagadas" nas práticas institucionais, textuais e vivenciais que caracterizam a cultura escolar e a experiência professor/ aluno dentro de determinados tempo, espaço e local.

As licenciaturas em Música, portanto, podem ser 
consideradas como terrenos em que uma ideologia musical, ligada historicamente aos conservatórios de música, tem fabricado "certezas musicais hegemônicas".

Lucy Green (1988) afirma que a ideologia confere significado àquilo que chamamos de "verdade". Para a autora, ideologia pode ser entendida como uma força mental coletiva que nasce e se perpetua a partir de nossas relações materiais e sociais.

Green relaciona a ideologia musical à dessocialização da experiência musical:

[A ideologia musical] baseia-se na suposição de que a música é uma criação atomizada e fragmentada de indivíduos isolados, e que alcança grandiosidade quando transcende sua aparente singularidade e passa a pertencer ao universal, ao eterno, ao a-histórico . (GREEN, 1988, p. 5, tradução nossa)

Nesta perspectiva, a autora mostra que esta ideologia, ao despir a experiência musical de seu caráter social, não apenas nega a historicidade e mutabilidade da música, dos valores e experiências musicais, mas, ao fazê-lo, constrói-se implicitamente como um sistema para a cotação do valor musical: "quanto mais capaz de reificação, mais grandiosa é a música" (GREEN, 1988, p. 11, tradução nossa).

Quando incorporada nos agentes, esta ideologia ratifica e mantém, imanentemente, a hegemonia de uma instituição musical que, junto de seus produtos reificados, fazem-se ser vistos como superiores. Entra em cena a tradição seletiva, que separa a música superior de uma música de massa, profana, classificadas como não sendo realmente musicais. Ao ser incorporada nos agentes, esta ideologia cria disposições que orientam as práticas, as percepções, enfim, os significados musicais.

Ancorado no conceito gramsciniano de hegemonia, Apple $(2006$, p. 39) a define como um processo que atua para saturar a consciência de maneira que 0 mundo educacional, econômico e social que vemos e como qual interagimos, bem como as interpretações do senso comum que a ele atribuímos, se torna o mundo tout court, o único mundo. Assim, para este autor, a hegemonia se refere não à acumulação de significados que estão em um nível abstrato em algum lugar "da parte superior de nossos cérebros". Ao contrário, a hegemonia se refere a um conjunto organizado de significados, valores e ações que são vividos.
Desta forma, o conservatório, desde sua criação, tem dado o tom da educação musical, instituindo suas práticas possíveis, organizando os significados, valores e ações referentes ao ensino musical. E o consenso sobre estas práticas conservatoriais perpassa não somente os cursos de Licenciatura em Música, como também as escolas especializadas, projetos sociais e as representações do senso comum sobre música e ensino musical.

A visão de música, de músico e, por conseguinte, de ensino musical forjados no conservatório pode ser caracterizada como hegemônica na medida em que, quando experimentados como práticas, são tidos como a versão natural do possível, como realidade, como verdade.

Contudo, deve-se ressaltar que não é uma organização estática, apesar de durável e estável. Ela é re-produzida e atualizada a todo instante, impulsionadas pelo movimento da história sem perder suas características principais.

O Conservatório foi criado com o status de instituição responsável pelo ensino da música, o ensino de uma cultura musical dominante, com vistas à sua conservação, perpetuação. Esta cultura dominante passa a ser incorporada não só por aqueles que passam pelo espaço do conservatório, mas por todos os que, de alguma forma, entram em contato com seu sistema de práticas e valores.

Ao transmitir esta cultura dominante, o Conservatório segue realizando o que Williams (1992) chama de tradição seletiva, ou seja, um processo de transmissão de uma seleção da cultura entendida como "a tradição", selecionando "o passado significativo". Desta forma, determinado tipo de música e, portanto, de práticas de se fazer e ensinar música, são escolhidos e legitimados; ao passo que todas as outras formas de se pensar e fazer música são negadas, excluídas e destituídas de valor.

Com a naturalização deste processo, foi-se instituindo um paradigma, uma cultura musical dominante, foi-se estabelecendo um sistema de valorização do capital musical, a partir do qual práticas e sentidos musicais vêm sendo hierarquizados. Tudo isto não ocorre sem lutas, com certeza. Neste jogo que se configura, pode-se perceber a luta pela valorização de outras formas de fazer música, outras formas de percebê-la, ensiná-la e 
de pensá-la. Esta luta pode ser apreendida como uma disputa dos agentes pela valorização do seu próprio capital, na tentativa de alcançar posições mais privilegiadas no interior do campo.

Cabe ressaltar que esta ideologia musical instituída pelo conservatório não é própria apenas de uma classe, ou de determinadas escolas de música. Não é uma ideologia imposta. É, antes disso, compartilhada por todos, em maior ou menor grau. É hegemônica.

\section{Ideologia e Currículo}

A partir de uma primeira aproximação analítica dos documentos curriculares selecionados (diretrizes e projetos pedagógicos de quatro diferentes cursos de Licenciatura em Música brasileiros) para a escrita da tese de doutoramento (PEREIRA, 2013) foi possível observar como esta ideologia musical e as demais características conservatoriais se materializam nos projetos pedagógicos dos cursos.

Castagna (2004) mostra que o ensino musical, no Brasil, era dividido em duas modalidades: um ensino de caráter mais teórico, "especulativo", praticado nas grandes catedrais; e outro mais prático, dominante, que visava ao exercício prático do ofício musical nas celebrações e festas religiosas.

A criação do Conservatório no Brasil, em 1848, acaba por unificar estes dois tipos de ensino musical que eram praticados desde a chegada dos jesuítas:

Desde fins da Idade Média, o ensino musical europeu diferenciara-se em duas categorias distintas que somente seriam reunidas nos conservatórios do séc. XIX. Em Universidades, Seminários e Catedrais, nas quais se estudava a música como uma disciplina do quadrivium, era ministrada a música especulativa, ou seja teórica, com a visitação dos tratados antigos ou contemporâneos, destinada à investigação dos elementos constitutivos da músi$c a$, diferentemente da música prática, destinada ao canto e à execução instrumental. (BINDER e CASTAGNA, 1996, s.p.)

As DCN Música (2004) indicam a manutenção do ensino da música prática e especulativa: os conteúdos devem ser distribuídos em Específicos, Teórico -Práticos e Básicos. A formação abrange, portanto, outras áreas do conhecimento em diálogo com a música, inserindo-a num contexto mais amplo.
Os Conteúdos Específicos não são detalhados, mas indicam a centralidade da performance ao prescrever a abrangência ao "conhecimento instrumental, composicional, estético e de regência". Este caráter dominante da performance é reforçado nos Conteúdos Teórico-Práticos, que abrangem "o exercício da arte musical" (BRASIL, 2004).

Como afirmado anteriormente, a análise dos documentos curriculares confirmou uma mesma concepção do que seja "conhecimento específico musical", indicando a existência de uma matriz disposicional que orienta a construção curricular. E esta matriz disposicional está intimamente relacionada à ideologia propagada pelos conservatórios, como pode se observar na Figura 1 (próxima página):

A Figura 1, construída a partir dos documentos curriculares e de criação do Conservatório Imperial de Música (1847), do Instituto Nacional de Música $(1890,1931,1937)$ e das Licenciaturas em Música da UFMG (2001), UFMS (2011), UFRJ (2008) e UFSJ (2008), nos permite detectar, claramente, a presença de uma matriz conservatorial que tem perdurado nos currículos e incorporado, nos estudantes, disposições que (re)produzem uma ideologia ligada à hegemonia do valor da música erudita.

Esta afirmação decorre do fato de que a organização curricular é construída a partir do e para o sistema de cotação do valor musical atrelado à música erudita. Neste sentido, depreende-se, da análise destes documentos curriculares, que o conhecimento oficial é ditado pelas normas definidas pela chamada música erudita.

Conhecimento oficial é o produto de uma seleção da cultura que é tornada legítima através da legislação. Também esta seleção não é neutra, mas interessada, servindo aos interesses de alguém:

\footnotetext{
Considerarei as escolas como instituições que incorporam tradições coletivas e intenções humanas que, por suas vez, são os produtos de ideologias sociais e econômicas identificáveis. (...) O currículo das escolas responde a recursos ideológicos e culturais que vêm de algum lugar e os representa. Nem as visões de todos os grupos estão representadas, nem os significados de todos os grupos recebem respostas. (APPLE, 2006, p. 84).
}

As diretrizes curriculares nacionais não definem uma "música oficial", os documentos curriculares expressam a concepção que suas instituições têm 


\section{CONSERVATÓRIO IMPERIAL DE MÚSICA (1847)}

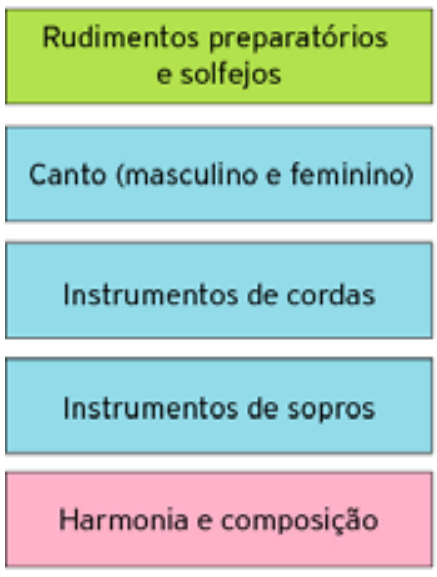

NSTITUTO NACIONAL DE MÚSICA (1931/1937)

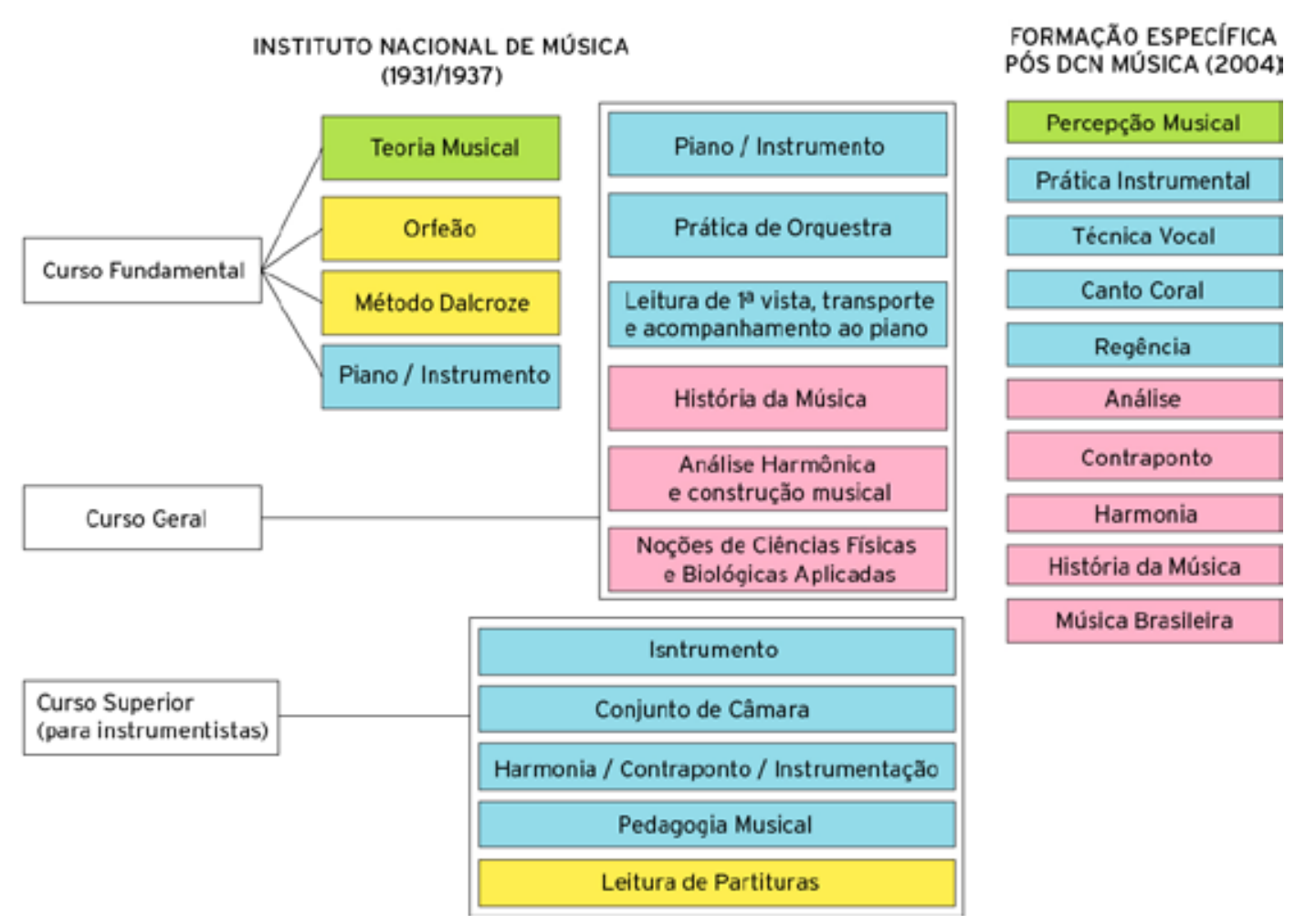

a) Rudimentos

b) Exercícios de Solfejo

b) Exercícios de Solfejo

\section{Piano}

Harpa

Órgão

Violino

Violloncelo

Contrabaixo

Flauta

Oboé e Fagote

Clarineta

Trompa, Trombone

\section{Seçăo Preparatória e Complementar de Composição}

Harmonia, acompanhamento, contraponto e fuga

Composição e Instrmentação

Seção Literária

\section{História e Estética da Música}

Figura 1 - Formação Musical do Conservatório às práticas curriculares pós DCN Música (2004)

de música e de educação musical. A análise destes documentos permitiu revelar, portanto, os princípios ideológicos que norteiam a definição da música oficial, e como este conhecimento oficial é distribuído em disciplinas. 
Nos projetos pedagógicos analisados na tese de doutoramento (PEREIRA, 2013) bem como os analisados por Mateiro (2010) na América Latina, observa-se a centralidade ocupada pela música erudita, com grande ênfase na música europeia.

As ementas das disciplinas ilustram e reforçam esta afirmação. As disciplinas de Análise Musical e Contraponto no curso da UFMG, por exemplo, são estruturadas a partir da música erudita ocidental:

Quadro 1 - Música erudita como conhecimento oficial nas ementas da disciplina Análise Musical da UFMG

\begin{tabular}{|l|l|}
\hline \multicolumn{2}{|c|}{ UFMG - Ementas da Disciplina Análise Musical } \\
\hline \multirow{2}{*}{ Análise Musical I } & $\begin{array}{l}\text { Estudo das ferramentas básicas de análise } \\
\text { musical. Estudo das formas barrocas: Suíte e } \\
\text { Fuga. Análise articulatória e motívica. Relaçōes } \\
\text { da harmonia com a macroforma. Estudo } \\
\text { comparativo da transformação das formas } \\
\text { Suite e Fuga em repertório do século XX. }\end{array}$ \\
\hline Análise Musical II & $\begin{array}{l}\text { EEstudo da Sonata clássica: esquemas formais, } \\
\text { harmonia, elaboração temática. O Lied: relação } \\
\text { texto e música. As formas no Romantismo: } \\
\text { Prelúdios de Chopin e exemplos de Wagnere } \\
\text { Brahms. }\end{array}$ \\
\hline Análise Musical III & $\begin{array}{l}\text { Estudo das principais tendências musicais do } \\
\text { século XX. Debussy: a libertação da harmonia } \\
\text { funcional e as formas resultantes da manipu- } \\
\text { lação dos materiais. Strawinsky: o ritmo como } \\
\text { elemento de construção, a forma-montagem. } \\
\text { Varèse: novos paradigmas de sonoridade e } \\
\text { organização formal. Escola de Viena: a tonali- } \\
\text { dade e o dodecafonismo. Exemplos de autores da } \\
\text { segunda metade do século XX. }\end{array}$ \\
\hline
\end{tabular}

Fonte: Quadro elaborado a partir de informações contidas em UFMG (2001).

Quadro 2 - Música erudita como conhecimento oficial nas ementas da disciplina Contraponto da UFMG

\begin{tabular}{|l|l|}
\hline \multicolumn{2}{|c|}{ UFMG - Ementas da Disciplina Contraponto } \\
\hline Contraponto I & $\begin{array}{l}\text { Origens do contraponto. O uso dos modos na } \\
\text { polifonia do século XVI. Ritmo, melodia, cadên- } \\
\text { cias, imitação. O contraponto renascentista a 2 e } \\
\text { 3 vozes: estudo das espécies e contraponto livre. } \\
\text { Análise do repertório do século XVI (G.P. Palestri- } \\
\text { na, O. de Lassus, C. Gesualdo. }\end{array}$ \\
\hline Contraponto II & $\begin{array}{l}\text { Estudo das espécies a 4 vozes. Contraponto } \\
\text { renascentista a 4 e 5 vozes. Análise do repertório } \\
\text { do século XVI: missas de G.P. Palestrina. Intro- } \\
\text { dução ao contraponto bachiano: análise das } \\
\text { Invenções a 2 e 3 vozes de J. S. Bach. }\end{array}$ \\
\hline Contraponto III & $\begin{array}{l}\text { Contraponto bachiano. Estudo sistemático de } \\
\text { elementos estruturais da Fuaga: sujeito, resposta, } \\
\text { contra-sujeito, partes livres, divertimentos, stretti } \\
\text { etc. Análise de Fugas do Cravo-Bem-Temperado, } \\
\text { enfocando as estruturaçöes formal, polifônica, } \\
\text { harmônica e rítmica. Visão geral da obra de Bach }\end{array}$ \\
\hline Contraponto IV & $\begin{array}{l}\text { Conclusão do estudo da Fuga bachiana: análise } \\
\text { da Oferenda Musical e da Arte da Fuga. A Fuga } \\
\text { pós-bachiana: análise de obras de Mozart, } \\
\text { Beethoven, Brahms, Bartok, Villa-Lobos, Berg, } \\
\text { etc. }\end{array}$ \\
\hline
\end{tabular}

Fonte: Quadro elaborado a partir de informações contidas em UFMG (2001). 
O mesmo pode ser observado nas ementas da disciplina Linguagem e Estruturação do curso da UFMS, como mostra o Quadro 3 abaixo:

Quadro 3 - Música erudita como conhecimento oficial nas ementas da disciplina Linguagem e Estruturação Musical da UFMS

\begin{tabular}{|l|l|}
\hline \multicolumn{2}{|c|}{ UFMS - Ementas da Disciplina Linguagem e Estruturação Musical } \\
\hline Análise Musical I & $\begin{array}{l}\text { Análise sistemática de obras do repertório } \\
\text { musical tradicional, procurando compreender os } \\
\text { princípios de organização dos materiais musicais } \\
\text { correlacionados aos aspectos formais, com } \\
\text { ênfase no repertório do século XVIII trabalhado à } \\
\text { luz da teoria schenkeriana. }\end{array}$ \\
\hline Análise Musical II & $\begin{array}{l}\text { Análise sistemática de obras do repertório } \\
\text { musical tradicional, procurando compreender os } \\
\text { princípios de organização dos materiais musicais } \\
\text { correlacionados aos aspectos formais, com } \\
\text { ênfase no repertório do século XVIII trabalhado à } \\
\text { luz da teoria schenkeriana. }\end{array}$ \\
\hline Análise Musical III & $\begin{array}{l}\text { Análise sistemática de obras do repertório } \\
\text { musical tradicional, procurando compreender } \\
\text { os princípios de organização dos materiais } \\
\text { musicais correlacionados aos aspectos formais, } \\
\text { com ênfase nos repertórios do século XIX e } \\
\text { início do XX. }\end{array}$ \\
\hline Análise Musical IV & $\begin{array}{l}\text { Análise sistemática de obras do repertório } \\
\text { musical tradicional, procurando compreender } \\
\text { os princípios de organização dos materiais } \\
\text { musicais correlacionados aos aspectos formais, } \\
\text { com ênfase nos repertórios do século XIX } \\
\text { e início do XX. }\end{array}$ \\
\hline
\end{tabular}

Fonte: Quadro elaborado a partir de informações contidas em UFMS (2011).

Na disciplina Contraponto, a centralidade da música erudita fica clara na bibliografia sugerida:

Quadro 4 - Música erudita como conhecimento oficial na disciplina Contraponto I da UFMS

\begin{tabular}{|l|l|}
\hline \multicolumn{2}{|c|}{ UFMS - Ementas e Bibliografia Básica da disciplina Contraponto I } \\
\hline Ementa & $\begin{array}{l}\text { Introdução ao pensamento contrapontístico e } \\
\text { resumo histórico de seu desenvolvimento. } \\
\text { Diretrizes básicas: conceitos de consonância e } \\
\text { dissonância; tratamento das dissonâncias: } \\
\text { movimento melódico e movimento harmônico a } \\
\text { duas vozes. }\end{array}$ \\
\hline Bibliografia Básica & $\begin{array}{l}\text { CARVALHO, Any Raquel. Contraponto Modal } \\
\text { Manual Prático.Porto Alegre: Sagra Luzzatto, } \\
\text { 200O. } \\
\text { KOELLREUTER, Hans Joachin. Contraponto } \\
\text { Modal do século XVI - Palestrina. Brasilia: } \\
\text { Musimed, 1996. } \\
\text { SCHOENBERG, Arnold. Preliminary Exercises in } \\
\text { Counterpoint. London: Faber \& Faber, 1982. }\end{array}$ \\
\hline
\end{tabular}

Fonte: Quadro elaborado a partir de informações contidas em UFMS (2011). 
E na disciplina Flauta Transversal, pelo repertório selecionado:

Quadro 5 - Música erudita como conhecimento oficial na disciplina Instrumento Musical Flauta Transversal da UFMS

\begin{tabular}{|c|c|}
\hline Ementa & $\begin{array}{l}\text { Estudo de repertório da literatura instrumental } \\
\text { de distintos períodos da história da música, } \\
\text { enfatizando a música brasileira e contem- } \\
\text { porânea. Desenvolvimento das habilidades } \\
\text { técnicas necessárias à execução de obras da } \\
\text { literatura referida. }\end{array}$ \\
\hline Bibliografia Básica & $\begin{array}{l}\text { ANDERSEN, K. J. } 24 \text { Studies, Op.33. New York: } \\
\text { International Music Co. } \\
\text { BACH, C. P. E. Sonata in a minor for solo flute. } \\
\text { Kassel: Bärenreiter, 1986. [Partitura]. } \\
\text { BACH, J. S. Zwei Sonaten für Flöte und Basso } \\
\text { continuo, Zwei Sonaten für Flöte und obligates } \\
\text { Cembalo. Kassel: Bärenreiter, 1966. [Partitura]. } \\
\text { DAVIES, J. Scales \& Arpeggios for the flute. } \\
\text { London: Boosey \& Hawkes, } 1962 . \\
\text { GARIBOLDI, G. Vingt Petites Études. Paris: } \\
\text { Alphonse Leduc Éditions Musicales, 1952. } \\
\text { HAENDEL, G. F. Elf Sonaten für Flöte. Kassel: } \\
\text { Bärenreiter, 1995. [Partitura]. } \\
\text { MOYSE, M. De la Sonorité. Art et technique. Paris: } \\
\text { Alphonse Leduc Éditions Musicales, } 1934\end{array}$ \\
\hline
\end{tabular}

Na UFSJ, é possível observar o foco na música erudita na disciplina Instrumento ou Canto, por exemplo:

Quadro 6 - Música erudita como conhecimento oficial na disciplina Instrumento ou Canto da UFSJ

\begin{tabular}{|l|l|}
\hline \multicolumn{2}{|c|}{ UFSJ - Ementas e Bibliografia Básica da disciplina Instrumento ou Canto } \\
\hline Ementa & $\begin{array}{l}\text { Desenvolvimento de competências para a inter- } \\
\text { pretação de repertório solístico e camerístico da } \\
\text { música erudita ocidental e brasileira composto } \\
\text { para o instrumento. }\end{array}$ \\
\hline
\end{tabular}

Fonte: Quadro elaborado a partir de informaç̃̃es contidas em UFSJ (2008).

E também, de maneira similar à UFMS, na bibliografia sugerida para a disciplina Contraponto: 
Quadro 7 - Música erudita como conhecimento oficial na disciplina Contraponto da UFSJ

\begin{tabular}{|l|l|}
\hline \multicolumn{2}{|c|}{ UFSJ - Ementas e Bibliografia Básica da disciplina Contraponto } \\
\hline Ementa & $\begin{array}{l}\text { Desenvolvimento da compreensão e percepção } \\
\text { do contraponto modal e tonal, a duas e três } \\
\text { vozes e do estilo imitativo como recurso para } \\
\text { análise musical. }\end{array}$ \\
\hline Bibliografia Básica & $\begin{array}{l}\text { KOELLREUTTER, H.J.(Hans Joachim). Contrapon- } \\
\text { to modal do seculo XVI (Palestrina). São Paulo: } \\
\text { Novas Metas, c1989. 108p. } \\
\text { SCHOENBERG, Arnold. Exercícios preliminares } \\
\text { em contraponto. São Paulo: Via Lettera, 2001. } \\
\text { TRAGTENBERG, Lívio. Contraponto: uma arte de } \\
\text { compor. Săo Paulo: EDUSP, 1994. 266p. }\end{array}$ \\
\hline
\end{tabular}

Fonte: Quadro elaborado a partir de informações contidas em UFSJ (2008).

E Análise Musical:

Quadro 8 - Música erudita como conhecimento oficial na disciplina Análise Musical da UFSJ

\begin{tabular}{|c|c|}
\hline \multicolumn{2}{|c|}{ UFRJ - Ementas da Disciplina Harmonia e Morfologia } \\
\hline Ementa & $\begin{array}{l}\text { Desenvolvimento da compreensão estrutural do } \\
\text { discurso musical, sob aspectos micro e macrofor- } \\
\text { mais, tendo como referência um repertório } \\
\text { representativo da música ocidental e brasileira, } \\
\text { visando aplicação na interpretação musical. }\end{array}$ \\
\hline Bibliografia Básica & $\begin{array}{l}\text { GRELA, Dante. Análise musical: uma proposta } \\
\text { metodológica. Tradução Gilberto Carvalho. Belo } \\
\text { Horizonte: manuscrito do tradutor, [s.d.] (Original } \\
\text { em espanhol). } \\
\text { GUERRA-PEIXE C. Melos e harmonias acústica: } \\
\text { princípios da composição musical. São Paulo - } \\
\text { Rio de Janeiro: Irmãos Vitale, } 1988 \text {. } \\
\text { KOELLREUTTER, H. J. Harmonia funcional: } \\
\text { introdução à teoria das funções harmônicas. São } \\
\text { Paulo: Ricordi Brasileira, 1987. } \\
\text { SCHOENBERG, Arnold. Fundamentos da } \\
\text { composição musical. 3. ed. Traduçăo Eduardo } \\
\text { Sencman. São Paulo: EDUSP, } 1996 \text { (Original } \\
\text { inglês). }\end{array}$ \\
\hline
\end{tabular}

Fonte: Quadro elaborado a partir de informações contidas em UFSJ (2008). 
Quadro 9 - Música erudita como conhecimento oficial nas ementas da disciplina Harmonia e Morfologia da UFRJ

\begin{tabular}{|c|c|}
\hline \multicolumn{2}{|c|}{ UFRJ - Ementas da Disciplina Harmonia e Morfologia } \\
\hline Harmonia e Morfologia I & $\begin{array}{l}\text { Harmonia a } 4 \text { partes. As cadências e as marchas } \\
\text { harmônicas. Os acordes dissonantes naturais e } \\
\text { suas resoluções. A cifragem do Baixo Dado. } \\
\text { Análise de trechos harmonizados. }\end{array}$ \\
\hline Harmonia e Morfologia II & $\begin{array}{l}\text { A modulação aos tons vizinhos. Os acordes de } 7^{\text {a }} \\
\text { dissonante artificial e suas resoluções. Notas } \\
\text { melódicas. As marchas modulantes. O discurso } \\
\text { musical e seu paralelismo com o literário. As } \\
\text { pequenas formas binárias e ternárias. }\end{array}$ \\
\hline Harmonia e Morfologia III & $\begin{array}{l}\text { Canto Dado uníssono e modulante. Notas melódi- } \\
\text { cas. Os retardos nos acordes de } 3,4 \text { e } 5 \text { sons. Os } \\
\text { vários tipos de imitação. As alterações não } \\
\text { artificiais nos acordes de } 3 \text { e } 4 \text { sons. Invenções a } \\
\text { duas e três vozes de J. S. Bach. A Suíte de forma } \\
\text { clássica e suas características formais. }\end{array}$ \\
\hline Harmonia e Morfologia IV & $\begin{array}{l}\text { Alterações artificiais nos acordes de } 3,4 \text { e } 5 \\
\text { sons. A modulação a tons afastados e seus } \\
\text { diversos tipos. O pedal e seus tipos. Análise dos } \\
\text { Prelúdios e Fugas de J. S. Bach. }\end{array}$ \\
\hline Harmonia e Morfologia V & $\begin{array}{l}\text { O "Canto e o Baixo Alternados". A variaçăo. } \\
\text { Organização formal dos movimentos da Sonata } \\
\text { Clássica. Harmonia Instrumental. Introdução à } \\
\text { sonata de Haydn e Mozart. }\end{array}$ \\
\hline Harmonia e Morfologia VI & $\begin{array}{l}\text { A Harmonia Instrumental. A Orquestra. Os } \\
\text { valores estéticos da expressão instrumental. } \\
\text { Organização formal dos movimentos da Sonata } \\
\text { Clássica. Sonata de Beethoven. A Sonata cíclica. }\end{array}$ \\
\hline
\end{tabular}

Fonte: Quadro elaborado a partir de informações contidas em UFRJ (2008).

Gainza (2002, p. 115) declara que a capacitação básica oferecida pelos conservatórios é mantida atualmente - muitas vezes não só o conteúdo, mas as práticas - e inclui:

a) O solfejo (lido e entoado), em distintas claves, tonalidades, ritmos, etc., e a compreensão dos signos e indicações escritas referentes a matizes, articulações, etc;

b) A execução técnico-instrumental progressiva, mediante a aplicação de textos e materiais didáticos que, em sua maioria datam do século XIX;

c) O repertório musical, integrado pelas obras do gênero clássico ou erudito internacional e nacional, abarcando um período de cerca de duzentos anos sem ultrapassar as duas ou três primeiras décadas do século $X X$.
Nettl (2002, p. 34) completa, ainda, ressaltando que o fato de um estudante ocidental de música aprender um sistema teórico baseado amplamente numa parte específica do seu repertório - neste caso o do período entre 1720 e 1900 - indica o que nós consideramos como mais importante em nossa experiência musical.

Retornando à análise dos currículos selecionados, nota-se que o ensino prático e especulativo da música mantiveram-se reunidos no processo de formação, sendo o ensino teórico (notação) realizado em uma disciplina diferente da prática musical, mas ainda com um caráter propedêutico para esta última. E manteve-se, ainda, a centralidade de ambas neste processo. $O$ conhecimento específico musical é, portanto, caracterizado pela permanência histórica da prática musical da música escrita, enriquecida por informações sobre música (história, estética, técnicas e formas composicionais). 
As semelhanças na oferta de disciplinas de prática musical nos cursos analisados é flagrante, apesar de existirem pequenas diferenças - muitas vezes determinadas pelo número de professores no quadro permanente de cada um destes cursos. Todos eles propiciam aos licenciandos uma formação prática instrumental (às vezes mais aprofundadas em um único instrumento, às vezes mais geral, tomando esse instrumento como ferramenta para a musicalização), priorizando o teclado, o violão e a flauta doce. Além da regência, importante no âmbito escolar para a formação de bandas estudantis.

Portanto, a análise do conhecimento oficial e de sua distribuição nos documentos curriculares permite-nos observar uma história incorporada, feita natureza: uma história fortemente marcada pela instituição conservatorial.

É possível mapear influências de uma ideologia musical fortemente marcada pelo sistema de vaIor da música erudita, como descrito por Green (1988), indicando que esta ideologia, produto do movimento histórico, foi incorporada e tornada uma matriz disposicional.

Pierre Bourdieu compreende esta matriz disposicional como habitus:

História incorporada, feita natureza, e por isso esquecida como tal, o habitus é a presença operante de todo o passado do qual é o produto: no entanto, ele é o que confere às práticas sua independência relativa em relação às determinações exteriores do presente imediato. Essa autonomia é a do passado operado e operante que, funcionando como capital acumulado, produz história a partir da história e garante assim a permanência na mudança que faz o agente individual como mundo no mundo. (BOURDIEU, 2009, p. 93)

As nossas ações seriam engendradas por disposições internalizadas ao longo de nossos processos de socialização, funcionando como:

[...] sistemas de disposições duráveis, estruturas estruturadas predispostas a funcionar como estruturas estruturantes, isto é, como princípio gerador e estruturador das práticas e das representações que podem ser objetivamente "reguladas" e "regulares" sem ser o produto da obediência a regras, objetivamente adaptadas a seu fim sem supor a intenção consciente dos fins e o domínio expresso das operações necessárias para atingi-los e coletivamente orquestradas, sem ser o produto da ação organizadora de um regente (BOURDIEU, 1983, p. 61 , grifos no original).
Ao trazer para a Música, propomos então a noção típico-ideal de habitus conservatorial (PEREIRA, 2013), matriz disposicional relacionada à música que teria se constituído no movimento histórico dos cursos de música no Brasil e sido incorporada nos sujeitos ao longo do tempo.

A noção de habitus ajuda-nos a explicar a uniformidade observada na distribuição do conhecimento musical nos currículos analisados, apesar de não haver uma prescrição disciplinar nas diretrizes curriculares nacionais. Ainda que existam pequenas variações nas diferentes propostas curriculares, poderíamos reconhecer o que Bourdieu chama de homologia das práticas, ou seja, uma diversidade na homogeneidade (BOURDIEU, 2009, p. 99). Nesta perspectiva, práticas curriculares orientadas por este habitus conservatorial selecionam a música erudita como conhecimento legítimo e como parâmetro da estruturação de disciplinas e de hierarquização dos capitais culturais em disputa.

Em decorrência disso, a notação musical acaba por ocupar um lugar central nos currículos, uma vez que dela depende a maior parte das disciplinas que tratam da música erudita.

Dessa forma, cria-se uma estrutura curricular de estudo da música que, por si só, privilegia a música erudita e afasta outras possibilidades de práticas musicais que estariam mais relacionadas com a vida cotidiana dos alunos. Esta estrutura ganha ainda mais força com sua adequação aos critérios de seleção do conhecimento escolar.

Quando as "outras músicas" são abordadas no currículo, ou o são por meio de sua excentricidade, ou esta abordagem se dá a partir da lógica erudita, ou seja, como conteúdo a ser trabalhado a partir do instrumental erudito.

Ainda que os conhecimentos pedagógicos musicais se refiram às formas de como ensinar o conhecimento musical legitimado (em especial a notação), pode-se esperar uma crescente preocupação com a figura do professor de música, pois a universidade não está tão alienada das demandas da sociedade, embora a figura do músico professor ainda seja predominante.

Estas mudanças indicam que o conservatório não é meramente reproduzido, mas atualizado. 
E as atualizações - neste caso inovações curriculares, ou de maneira mais precisa, tentativas de reformas curriculares - são realizadas a partir de matrizes conservatoriais incorporadas.

Reiteramos que não somos contra a prática conservatorial, que, apesar de todas as críticas que tem sofrido, apresenta inúmeras qualidades para a formação de artistas para o campo artístico musical. O que nos incomoda é observar que essa formação de artistas é privilegiada mesmo quando se trata da formação de professores para a escola regular, cuja função primordial seria a de intermediar músicas e seres humanos. Músicas, no plural, como afirma Penna (2010): tanto os produtos quanto os processos.

É nesta perspectiva que o habitus conservatorial tem comprometido o sucesso da implantação do ensino de música(s) (e não de um tipo de música tido como legítimo e valioso) na escola regular, ademais, um ensino que se propõe para todos (e não somente para os "talentosos").

\section{Considerações Finais}

As práticas orientadas por um habitus conservatorial criam um paradoxo nos cursos de Licenciatura em Música. Os princípios trabalhados nas disciplinas relacionadas à educação música - que se referem, por exemplo, ao respeito à diversidade, ao discurso musical dos alunos, à exploração deste discurso tão diversificado - acaba por colidir com a hegemonia da música erudita.

Como esperar que o professor de música respeite a diversidade musical e trabalhe o valor das várias manifestações musicais presentes no cotidiano escolar e da vida dos alunos se sua formação foi construída a partir de valores determinados e tidos como legítimos e superiores?

Como esperar esse respeito se quando estes professores ingressam no ensino superior eles próprios não têm seu discurso musical valorizado e levado em consideração?

Reforçamos, mais uma vez, que nossos questionamentos não pretendem excluir as práticas de música erudita da formação de professores. Pensamos ser fundamental, na formação do professor de música, uma sólida formação musical. Entretanto, é urgente refletir sobre o que tem significado para cada um de nós "formação musical sólida". Muitas vezes isso tem significado formação musical erudita e restringido outras possibilidades tão ricas e importantes quanto ela.

Não se trata de excluir, mas de integrar. Trata-se de desnaturalizar o sentido que temos atribuído a palavras como "Música" e "Ensino de Música". Muitas vezes empregamos estes termos em nossos discursos partindo do pressuposto de que estamos falando das mesmas coisas. É preciso estranhar para questionar, para enxergar melhor e compreender o que pensamos e o que fazemos.

Esse estranhamento é urgente para que, na busca por emancipar a crítica musical de nossos alunos, nos reconheçamos, muitas vezes, alienados em uma prática musical ideológica e, portanto, carentes nós mesmos de uma emancipação.

É fundamental que nos reconheçamos reféns de uma ideologia musical incorporada na forma de um habitus que orienta práticas preconceituosas, pretensamente a-sociais, homogeneizantes, massificadoras e alienantes.

É fato que esse habitus conservatorial se manifesta de diferentes formas, pois cada um de nós passou por diferentes processos de socialização. Reafirma-se o caráter típico-ideal do conceito, ou seja, ela nunca acontece na realidade, posto que está relacionado às diferentes formas que experenciamos a música e seu ensino ao longo das nossas vidas.

O conceito de habitus, em Bourdieu, surge como sendo capaz de conciliar a oposição aparente entre a realidade exterior e as realidades individuais. Para Setton (2002, p. 63), esta noção seria capaz de expressar o diálogo, a troca constante e recíproca entre o mundo objetivo e o mundo subjetivo das individualidades - o que remete a uma análise relacional que enfatiza o caráter de interdependência entre indivíduo e sociedade.

Habitus seria, portanto, uma subjetividade socializada e uma socialidade subjetivada. Desta forma, ainda que exista uma matriz comum (como o habitus conservatorial aqui proposto), esta se manifesta homologamente nas individualidades.

A proposta de pesquisa que nos lançamos, a partir deste entendimento, é a de mapear como o ha- 
bitus conservatorial se manifesta nas percepções sobre música e seu ensino de pessoas que não estão imersas diretamente nos cursos de Licenciatura em Música.

Os sujeitos desta pesquisa, que se pretende como um aprofundamento da investigação iniciada no doutorado, são os jovens do ensino médio; e o objetivo é problematizar como as percepções destes jovens sobre música e seu ensino tem influenciado as práticas de educação musical no espaço escolar.

Desta forma, pretende-se estudar o encontro das concepções dos professores de música (já formados e em formação) com as dos jovens do ensino médio no Brasil. Intenta-se, assim, colaborar para a inserção da música no espaço escolar, auxiliando nas reflexões sobre as práticas de educação musical nas escolas de educação básica.

O objetivo continua sendo refletir sobre o ensino de música, desnaturalizando práticas e buscando maneiras de ampliar o repertório não só musical, como de estratégias de ensino. Enriquecer a já consolidada prática musical erudita, propiciando o diálogo com novas formas de pensar e agir musicalmente. Promover um encontro de cada ser humano com sua própria musicalidade e com as musicalidades que o cercam, cada vez mais consciente das ideologias que definem suas práticas não somente musicais, mas sua forma de ser e estar no mundo.

\section{Referências}

APPLE, Michael. Ideologia e Currículo. $3^{a}$. Edição. Porto Alegre: Artmed, 2006.

BINDER, Fernando Pereira e CASTAGNA, Paulo. Teoria Musical no Brasil: 1734 - 1854. In: Revista Eletrônica de Musicologia, Vol. 1/2.Curitiba: UFPR, Dezembro de 1996. Disponível em: http://www.rem.ufpr.br/_REM/ REMv1.2/vol1.2/teoria.html\#em Acesso em 12/08/2011.

BRASIL. Resolução $n^{\circ} \mathbf{2}$, de 8 de março de 2004. Aprova as Diretrizes Curriculares $\mathrm{Na}-$ cionais do Curso de Graduação em Música e dá outras providências. Disponível em: http://portal. mec.gov.br Acesso em: 20 jul. 2010.

BOURDIEU, Pierre. Pierre Bourdieu - Sociologia (Org. ORTIZ, Ricardo). Editora Ática: São Paulo, 1983.
BOURDIEU, Pierre. 0 senso prático. Petrópolis: Editora Vozes, 2009.

CASTAGNA, Paulo. Prática musical religiosa na América Portuguesa. São Paulo: UNESP, 2004. Disponível em

http://www.ia.unesp.br/docentes/castagna/hmb/ HMB_2004_apostila04.pdf Acesso em: 11 jun. 2010.

DENARDI, Cristiane. A formação inicial do professor de música no curso de licenciatura em música da EMBAP (1961 - 1996). 2006. $136 f$. Dissertação (Mestrado em Educação). Curitiba, Pontifícia Universidade Católica do Paraná, 2006.

GAINZA, Violeta Hemsy de. Pedagogia Musical - Dos décadas de pensamiento y acción educativa. Buenos Aires: Lumen, 2002.

GIROUX, Henry e MCLAREN, Peter. Formação do Professor como uma contra-esfera pública: a pedagogia radical como uma forma de política cultural. IN: MOREIRA, Antonio Flávio; SILVA, Tomaz Tadeu da (orgs). Currículo, cultura e sociedade. São Paulo: Cortez Editora, p. 125 - 153, 1995.

GREEN, Lucy. Music on deaf ears - Musical meaning, ideology and education. Manchester: Manchester University Press, 1988.

GOODSON, I. Currículo: Teoria e História. Petrópolis: Editora Vozes, 3a. Edição, 1999.

JARDIM, Vera Lúcia Gomes. Da arte à educação: A música nas escolas públicas 1838 - 1971. 2008. 322f. Tese (Doutorado em Educação). São Paulo, Pontifícia Universidade Católica de São Paulo, 2008.

KLEBER, Magali Oliveira. Teorias Curriculares e suas implicações no Ensino Superior de Música: um estudo de caso. 2000. Dissertação (Mestrado em Música). São Paulo, Universidade do Estado de São Paulo, 2000.

MATEIRO, Teresa. Músicos, pedagogos y arte-educadores con especialidad en educación musical: un análisis sobre la formación docente en países suramericanos. Professorado Revista de curriculum y formación del professorado, vol. 14, n. 2, 2010, pp 29-40.

MOREIRA, Antônio Flávio Moreira; SILVA, Tomáz Antônio Tadeu. Currículo, Cultura e Sociedade. 
São Paulo, Cortez Editora, 1995.

NETTL, Bruno. What's to be learned? Comments on teaching music in the world and teaching world music at home. In: BRESLER, Liora; THOMPSON, Marmé (Ed.) The Arts in Children's Lives. Dordrecht: Kluwer Academic Publishers, $p$. $29-41,2002$.

PENNA, Maura. Música(s) e seu ensino. 2a. Ed. Porto Alegre, Editora Sulina, 2010.

PEREIRA, Marcus Vinícius Medeiros. 0 ensino superior e as licenciaturas em música: um retrato do habitus conservatorial nos documentos curriculares. Campo Grande: Editora UFMS, 2013.

POPKEWITZ, Thomas S.; FENDLER, Lynn (orgs.). Critical Theories in Education. New York and London: Routledge, 1999.

SETTON, Maria das Graças Jacintho. A teoria do habitus em Pierre Bourdieu: uma leitura contemporânea. Revista Brasileira de Educação, Rio de Janeiro, n.20, p.60-70, maio/ago. 2002.

SILVA, Janaína Girotto. “o Florão mais belo do Brasil": O Imperial Conservatório de Música do Rio de Janeiro / 1841 - 1865. 2007. 248f. Dissertação (Mestrado em História Social). Rio de Janeiro, Universidade Federal do Rio de Janeiro, 2007.

UFMG. REUNI (Projeto Pedagógico dos cursos noturnos da Escola de Música da UFMG). Belo Horizonte, 2001.

UFMS. Projeto Pedagógico do Curso de Música. Campo Grande, 2011.

UFRJ. Curso de Licenciatura em Música - Projeto Pedagógico. Rio de Janeiro, 2008.

UFRJ. Matriz Curricular do Curso de Licenciatura em Música. Rio de Janeiro, 2009.

UFSJ. Projeto Pedagógico - Curso de Música. São João Del-Rey, 2008.

VIEIRA, Lia Braga. A construção do professor de música: o modelo conservatorial na formação e na atuação do professor de música de Belém do Pará. 2000. 187f. Tese (Doutorado em Educação). Campinas, Unicamp, 2000. WILLIAMS, R. Cultura. Rio de Janeiro: Editora Paz e Terra, 1992.

\section{Sobre 0 autor}

Marcus Vinícius Medeiros Pereira é Doutor em Educação pela Universidade Federal de Mato Grosso do Sul e Mestre em Música - Performance/ Piano pela Universidade Federal de Minas Gerais, tendo sido orientado pela Prof. Dr. a Margarida Borghoff. Graduou-se no curso de Bacharelado em Piano nesta mesma instituição na classe do Prof. Dr. Miguel Rosselini, em 2005. É integrante do Grupo de Pesquisa Resgate da Canção Brasileira (Escola de Música da UFMG), onde, além das atividades de pesquisa, atua como divulgador do gênero por meio de recitais em vários estados do Brasil. É pesquisador do Observatório de Cultura Escolar (PPGEdu - UFMS), onde desenvolve pesquisas que têm como objeto o currículo, a cultura, a escola e a cultura escolar. É autor do livro "O Ensino Superior e as Licenciaturas em Música: um retrato do habitus conservatorial nos documentos curriculares" e organizador, ao lado de Fabiany de Cássia Tavares Silva, do livro "Observatório de Cultura Escolar: estudos e pesquisas sobre escola, currículo e cultura escolar", ambos publicados em 2013 pela Editora UFMS. Entre 2009 e 2014, foi professor do curso de Licenciatura em Música da Universidade Federal de Mato Grosso do Sul. Atualmente é professor do Departamento de Música da Universidade Federal de Juiz de Fora e docente permanente no Programa de Pós-Graduação Música em Contexto da Universidade de Brasília. Está à frente do projeto que toma o Acervo Vicente de Paula Medeiros como objeto de investigação, com vistas à sua organização, sistematização, disponibilização e estudo das práticas musicais do início do século XX no interior do Brasil. Paralelamente, tem se dedicado também ao estudo da constituição de um habitus musical híbrido nos processos de socialização de jovens do Ensino Médio. 